\title{
Pela consolidação da sociologia e da antropologia das emoções no Brasil*
}

\author{
Mauro Guilherme Pinheiro Koury**
}

Resumo: Este artigo tem por objetivo realizar uma breve panorâmica da situação da sociologia e da antropologia das emoções no Brasil, desde o seu surgimento, no final da primeira metade da década de 1990, até o presente. Baseia-se, entre outras fontes, em dados recolhidos em congressos e encontros realizados no Brasil e na América Latina, que tiveram grupos de trabalho em antropologia e sociologia das emoções, ou temas a elas correlatos.

Palavras-chave: sociologia das emoções; antropologia das emoções; estado da arte da sociologia e da antropologia das emoções; consolidação da área disciplinar.

\section{O que é antropologia e sociologia das emoções?}

A sociologia e a antropologia das emoções se constituíram como subárea de conhecimento das disciplinas antropologia e sociologia, resultado de um processo iniciado nos Estados Unidos nos anos de $1970^{1}$. No Brasil, o seu surgimento e a luta pelo reconhecimento e processo de consolidação aconteceu quase duas décadas depois, nos anos de 1990.

A constituição dessas novas disciplinas deu-se como um processo de busca de rejuvenescimento da teoria social, permitindo uma releitura da tradição sociológica e antropológica, desde os seus clássicos. Esta nova leitura foi influenciada, principalmente, pela filosofia francesa de Derrida e Foucault e pela filosofia social de Simmel e através da redescoberta do processo civilizador, de Norbert Elias (1990; 1993), entre outros autores.

Nos Estados Unidos, a revisão da teoria social que gestou e permitiu os primeiros passos da antropologia e da sociologia das emoções, deu-se pari passu à redescoberta das filiações interacionistas desenvolvidas pelo que se convencionou chamar de Escola de Chicago, e uma revisão e crítica do estrutural-funcionalismo parsoniano, dominante desde o final da década de 1940 no pensamento social local². A sociologia e a antropologia das emoções espalharam-se pelo mundo, com construções teórico-metodológicas diversas, e até mesmo conflitantes, na busca de situar as emoções como categoria central para se pensar a inter-relação entre indivíduo e sociedade: fundamento da constituição das ciências sociais.

\section{* Conferência realizada a convite do Grupo de Pesquisa Cultura, Sociabilidades e Sensibilidades Urbanas do Centro de Recursos Humanos da Universidade Federal da Bahia, em 3 de maio de 2012 \\ ** Doutor em sociologia e professor de Programa de Pós-Graduação em Antropologia da Universidade Federal da Paraíba; coordenador do Grupo de Pesquisa em Antropologia e Sociologia das Emoções (Grem) da mesma universidade. <maurokoury@ gmail.com>}

1. Ver, entre outros, Kemper (1990); Lutz \& White (1986); Svasek (2006); Röttger-Rössler (2008).

\section{Sobre a}

influência do projeto parsoniano e sua influência na antropologia americana dos anos de 1940 e 1950, ver Adam Kuper (2002) especialmente 0 capítulo 2, "A visão das ciências sociais: Talcott Parsons e os antropólogos americanos", p. 73-102. 
3. É importante frisar que os estudos sistemáticos em antropologia e sociologia das emoções na América Latina são, ainda, mais recente do que no Brasil, sendo os primeiros esforços nessa direção datados do final desta primeira década do século XXI, isto é, 2008, com o surgimento do Grupo de Trabalho em Sociologia das Emoções e do Corpo no Congresso da Associação LatinoAmericana de Sociologia (Alas), na Argentina. Note-se, por outro lado, que na antropologia, um Grupo de Trabalho em Antropologia das Emoções aparece um pouco mais cedo, em 2003, através do Grupo de Pesquisa em Antropologia e Sociologia das Emoções (Grem) e coordenado pelo autor deste artigo.
No Brasil, já existem algumas pesquisas e ensaios que tentam apresentar e compreender esse processo de formação de uma área temática que traz as emoções para o centro dos debates sociais e culturais, como categoria analítica central. Nesta direção, conta-se, entre outros, com a tese ainda inédita de Torres (2009), os livros e artigos de Koury (2004; 2005; 2009) e o ensaio de Rezende e Coelho (2010), que buscam situar o debate e os caminhos da antropologia e da sociologia das emoções no cerne da tradição sociológica e antropológica brasileira e mundial.

Este artigo, assim, tem por objetivo realizar uma breve panorâmica da situação da sociologia e da antropologia das emoções no Brasil, desde o seu surgimento, no final da primeira metade da década de 1990, até o presente. Baseia-se, entre outras fontes, em dados recolhidos em congressos e encontros realizados no Brasil e na América Latina $^{3}$, que reuniram grupos de trabalho em antropologia e sociologia das emoções, ou temas a elas correlatos.

\section{Quem e o que se está produzindo em antropologia e sociologia das emoções no Brasil, nestes últimos vinte anos?}

Como já indicado acima, a sociologia e a antropologia das emoções no Brasil tem uma vida bem recente. Surgem como postulação afirmativa de campos disciplinares que se expandem no país, principalmente a partir de meados de 1990. A discussão e as análises sobre emoções e as suas interfaces com a cultura e a sociedade, porém, têm uma vida mais longa e podem ser mesmo vinculadas com as obras e os estudiosos fundadores do pensamento das ciências sociais brasileiro.

Os trabalhos de Gilberto Freyre, Paulo Prado, Sérgio Buarque de Holanda sobre a construção e constituição da nação brasileira, passando por Roger Bastide, em sua longa estada no Brasil, e pelos trabalhos de Oracy Nogueira, entre tantos outros, já colocam a questão das emoções e das relações intersubjetivas no constructo social como uma das problemáticas definidoras da busca de identificação das bases compreensivas para a constituição da realidade brasileira. Porém, apesar das emoções estarem presentes e serem importantes para as pesquisas e os estudos das ciências sociais brasileiras de então, não foram usadas como objeto de pesquisa próprio, funcionando, no máximo, como variável interveniente na análise do social e da cultura.

De forma equivalente aos clássicos das ciências sociais, a cultura emocional foi trabalhada por esses precursores, no Brasil, de forma abstrata e subsumida nas análises estruturais sobre a sociedade brasileira. Este quadro analítico predominou sobre os estudos realizados pela antropologia e sociologia brasileiras até a segunda metade da década de 1980. Vale salientar, ainda, que na constituição dessas disciplinas na academia brasileira como disciplinas científicas, do final dos anos de 1930 até os 1960 
e 1970, a sociologia e a antropologia - sobretudo a primeira - procuraram afastar de suas análises os fantasmas da subjetividade, delimitando a objetividade das relações sociais como fundamento de análise.

O esforço em favor de criação de uma cultura acadêmica no país que aceitasse a antropologia e a sociologia, sobretudo como disciplina padrão e de rigor científico adequado para a análise do social, e de que suas análises contivessem padrões de verdades científicas a serem comprovadas e, possivelmente, submetidas ao crivo de aplicações por instituições e instâncias diversas no social, como o planejamento social, por exemplo, fizeram parte desse processo de formação e de consolidação de um pensamento das ciências sociais e, aqui, especificamente, da sociologia, no país.

Neste empenho de criação de um pensamento científico, as análises de um Gilberto Freyre e de um Sérgio Buarque de Holanda, por exemplo, foram discriminadas do campo científico das ciências sociais em busca de consolidação no país, por serem avaliadas como ensaísticas e subjetivas, isto é, sem o rigor científico adequado, e os seus autores considerados como precursores destes novos campos de saber que se abria no Brasil4. É importante enfatizar que a revisão da obra destes precursores, pelas ciências sociais, e suas contribuições para o pensamento social e para as ciências sociais no país, só começam a acontecer no final da década de 1980.

Desde o final da década de 1970, porém, os estudos de Roberto Da Matta já convocam os pesquisadores e os estudiosos das ciências sociais no país, a partir da antropologia, para prestarem atenção especial à questão das emoções. Embora ainda sem estabelecer em suas análises um parâmetro próprio para o tratamento das emoções, como categoria analítica. Em seus trabalhos e discussões sobre o Brasil, sobre o dilema do ser e de ser brasileiro, Da Matta (1979) levanta hipóteses nas quais os sentimentos e suas formas de expressão no social perpassam a constituição do público e do privado no país ${ }^{5}$.

Em A casa e a rua, Da Matta (1987) discute os conceitos de sociedade relacional e de sociedades individualistas, opondo os dois tipos de organização social delas oriundas e inter-relacionando à lógica brasileira inerente ao primeiro tipo de sociedade, isto é, ao de sociedade relacional. Este parâmetro analítico o acompanhará por quase toda a sua obra, na qual buscará entender o cotidiano brasileiro, seus rituais e modelos de ação, seus dilemas dentro de um método estrutural baseado, em amplos termos, na leitura de Marcel Mauss (1974) e, sobretudo, Louis Dumont (1985), sobre o problema do individualismo e de pessoa no social.

No esforço de compreensão da realidade brasileira e de seus dilemas, parte da análise do cotidiano e dos rituais, e dos modelos de ação social, através de uma costura ana-
4. Nesta direção, ver o importante debate durante mais de duas décadas (1940-1964) sobre a sociologia como ciência e o seu processo de consolidação entre Florestan Fernandes e Guerreiro Ramos, que traz luz a este debate.

5. Para uma análise crítica contemporânea à obra de Da Matta, e para uma revisão das interpretações do dilema brasileiro, ver Pina Cabral (2007); Souza (2000; 2001); Maciel (2007), entre outros. 
lítica que coloca em tensão a relação entre as noções de indivíduo e de pessoa, como categorias que se articulam de modo peculiar na formação do social e da cultura do país. Elabora, assim, uma leitura antropológica e sociológica da realidade brasileira, dentro de um modelo dual de análise, que contrapõe a pessoa em relação ao indivíduo, em um processo contínuo de distopia. Para Pina Cabral,

Assim, o sociocentrismo de Da Matta, contrariamente ao de Louis Dumont e Marcel Mauss, é distópico: o Brasil, afinal, não vai chegar à modernidade, vai ficar preso em um limbo indeciso em que a modernidade e a tradicionalidade se cancelam mutuamente e no qual só esse cancelamento mútuo permite a existência de "sociedade", de segurança. O Brasil é "dual", é "dilemático", porque o encontro dos dois mundos potencia a desumanidade de ambos (Pina Cabral, 2007: 98).

Os modelos de ação e rituais cotidianos, no Brasil, deste modo, envolvem uma oposição e, simultaneamente, uma espécie de aprisionamento, entre as duas lógicas presentes na sociabilidade local. Segundo Da Matta, uma lógica institucional, visível e superficial, da qual o indivíduo emerge como sujeito estatístico e é submetido a leis impessoais, e uma lógica culturalista, estruturante do imaginário e do inconsciente brasileiro, onde a pessoa emerge como ser relacional e se encontra submetido a esferas hierárquicas do sistema social.

Esta oposição e aprisionamento faz do dilema brasileiro uma relação sempre tensa, mas resolvida através de um sistema de dominância do componente pessoa sobre o outro componente, individualizante e abstrato, que restaura a harmonia dos conflitos entre a casa e a rua, através da lógica hierárquica inerente à atitude relacional, com referência ao sistema social presente na noção de pessoa. Para Da Matta, deste modo, a compreensão da realidade social brasileira, e o entendimento do dilema brasileiro, da cultura e da trama das emoções e sentimentos deles emersos se dão através de uma leitura estrutural da sociedade via distopia, isto é, utilizando as suas palavras "a de ser um indivíduo numa sociedade que tem seu esqueleto numa hierarquia [...]" (Da Matta: 1979: 188).

Da Matta, assim, rejeita uma análise que valoriza as relações subjetivas entre os sujeitos relacionais, e que parta de uma troca entre os indivíduos e a sociedade para a compreensão de um social. Pare ele, é através das leis, das normas e dos valores de um sistema social que se pode compreender o comportamento relacional entre indivíduos nele presentes.

Gilberto Velho foi outro autor importantíssimo na configuração de uma antropologia e de uma sociologia das emoções no Brasil. Velho, em seus estudos e pesquisas, 
enfatizou a cultura emocional, principalmente a das classes médias, no Brasil urbano contemporâneo, principalmente o carioca da Zona Sul da cidade. Como Da Matta, parte de uma dualidade estruturante da realidade brasileira entre os sistemas hierárquicos e os sistemas individualistas, e baseou o seu aporte para a construção e o entendimento da lógica da hierarquia no Brasil na análise dumoniana, entre os sistemas holistas e individualistas.

Diferente de Da Matta, contudo, que busca uma espécie de padrão único para a interpretação do ser social e cultural brasileiro, Velho partiu do pressuposto de uma diversidade de padrões comportamentais e de sistemas individualistas e holistas na sociedade nacional, e enfatizou a procura pela compreensão do social brasileiro das classe médias urbanas através da lógica individualista. Discute a emergência do indivíduo psicológico no Brasil urbano, e o individualismo crescente nas camadas médias urbanas das grandes metrópoles.

Enfatizou, também, os rearranjos familiares e de amizade, e a lógica individualista dos projetos de vida, em contraposição aos projetos societários e coletivos. Tais relevos e destaques aconteceram no interior de uma leitura teórico-metodológica, de grande influência simmeliana, que mistura a análise fenomenológica com a análise interacionista dos dois momentos importantes da escola de Chicago. Nesta última, principalmente, através de autores como Robert Park, George Mead, Herbert Blumer, Erving Goffman e Howard Becker, sem desprezar, contudo, a leitura atenta e atenciosa de autores da escola francesa, como, por exemplo, Marcel Mauss, Claude Lévi-Strauss e Louis Dumont.

Velho elaborou, deste modo, uma análise profunda e profícua sobre as questões ligadas à relação entre as formas de subjetividade e a objetividade na análise da cultura e do social, bem como, sobre a problemática das emoções e da cultura emocional urbana na contemporaneidade brasileira. Assim, problematizou a tensa relação entre os indivíduos e a cultura e sociedade, fazendo desta tensão um tema recorrente em sua obra.

As relações entre indivíduo, cultura e sociedade, tal como analisadas em Velho, marcam uma dualidade que parece manifestar-se e expressar-se de diferentes formas, em outras relações, como, por exemplo, nas relações entre o grupo e seus membros ou, nas relações existentes, ou não, entre os projetos individuais e os campos de possibilidade oferecidos para o seu aparecimento e realização. Do mesmo modo, nas tensões entre a questão das unidades individual e social, e da fragmentação nas sociedades complexas, ou, ainda, nas questões relacionadas às tensões permanentes entre o consenso e o conflito, e entre as normas e o desvio, na busca de demonstrar o caráter heterogêneo do urbano, onde diferentes projetos, individuais e coletivos, chocam-se e interpenetram-se em rearranjos sempre em movimento. 
A noção de projeto é um de seus conceitos fundamentais, no tratamento da questão da heterogeneidade mencionada, e das tensões relacionais entre indivíduos e a cultura em uma sociedade complexa. Para ele, seguindo de perto a análise realizada por Alfred Schutz (1970), a noção de projeto implica uma avaliação dos meios e dos fins das ações humanas coletivas e individuais, estando, portanto, fortemente vinculada a uma realidade objetiva e externa (Velho, 1981; 1986). O que leva o pesquisador, também, é claro, para uma avaliação consciente das condições subjetivas de elaboração dos projetos, estratégias montadas, e busca de caminhos para a sua concretização.

Assim, o conceito de projeto individual, para Velho, não é um fenômeno puramente interno e subjetivo, mas, formulado e elaborado dentro de um campo de possibilidades, e circunscrito histórica e culturalmente, tanto em termos da própria noção de indivíduo no social, quanto às temáticas, prioridades e paradigmas culturalmente existentes. Para ele, seguindo uma lógica simmeliana, cada indivíduo é um lócus de tensão entre os constrangimentos da cultura, que solicitam o enquadramento a padrões específicos, e outros constrangimentos de cultura, que pedem ao indivíduo autonomia e singularidade.

O equilíbrio entre estes constrangimentos faz parte da carga de pressões cotidianas e das tarefas diárias dos indivíduos nas sociedades ocidentais contemporâneas. O que o leva a desenvolver as temáticas sobre o ser no mundo, das ideologias individualistas, das alianças, das diferenças individuais, da questão geracional, da problemática da família, da psicologização das sociedades urbanas contemporâneas, da relação entre a racionalidade e as emoções, das relações entre a cultura objetiva e a cultura subjetiva - esta última cara à análise simmeliana -, onde a questão ascende como elemento compreensivo fundamental no jogo ambivalente de formação dos sujeitos sociais e individuais para a análise da sociabilidade urbana contemporânea. Além e principalmente, para o entendimento da emergência, da fundação e dos modos de agir e de significar dos indivíduos pertencentes às camadas médias urbanas, com ênfase na sociabilidade carioca, onde concentrou os seus estudos e pesquisas, de modo particular. Gilberto Velho, portanto, pode ser considerado como um dos autores fundamentais para a compreensão da questão das relações entre a subjetividade e a sociabilidade, que movimenta quadros teóricos e dá suporte interpretativo ao pensamento recente e estruturador de uma sociologia e de uma antropologia das emoções no Brasil. Pode ser considerado, dessa maneira, um precursor importante - e, talvez, o principal deste novo campo analítico que lida, desde os anos de 1990, com as relações entre as emoções, a cultura e a sociedade no país. 


\section{e a sociologia das emoções no Brasil}

Desde os anos de 1990, com o surgimento da sociologia e da antropologia das emoções como interesse de pesquisa no Brasil, há o esforço de consolidação destes campos disciplinares. Três grupos de pesquisa situados em diversas instituições acadêmicas brasileiras têm se movimentado no sentido do fortalecimento, da divulgação e da concretização destas áreas: o Grupo de Pesquisa em Antropologia e Sociologia das Emoções (Grem), criado em 1994, na Universidade Federal da Paraíba (UFPB); o Grupo de Pesquisa Transformações da Intimidade, que trabalha na Universidade Estadual do Rio de Janeiro (Uerj) desde 1998; e o Grupo de Pesquisa Cultura, Sociabilidades e Sensibilidades Urbanas, instituído desde 2010 na Universidade Federal da Bahia.

\section{O Grupo de Pesquisa em Antropologia e Sociologia das Emoções (Grem)}

Instituído como base de pesquisa em antropologia e sociologia das emoções, em 1994, pelo autor deste artigo, no Departamento de Ciências Sociais da UFPB, este grupo de pesquisa oficializa um núcleo temático iniciado nos anos 1990, onde as emoções são consideradas como categoria chave para a análise sociológica e antropológica. O Grem, desde o início, tem por objetivo a compreensão e análise da emergência da individualidade e do individualismo no Brasil urbano contemporâneo, enfatizando a questão da formação das emoções, enquanto cultura emocional, e desenvolvendo estudos e pesquisas sobre processos de formação e experiência de emoções específica nos planos societal e cultural: como o processo de luto, da morte e do morrer; dos medos; das formas de sociabilidades e das etiquetas sociais que envolvem as relações de amizade; dos processos de ressentimento e humilhação; e das formas de estabelecimento de laços de confiança e desconfiança entre as camadas médias urbanas no país ${ }^{6}$.

As pesquisas desenvolvidas e em desenvolvimento no Grem debruçam-se sobre as imagens e suas representações na conformação do homem comum urbano brasileiro. Debruçam-se, também, sobre as redundâncias, as ambivalências e as ambiguidades do ato executado ou expresso, sobre os silêncios, os discursos e as narrativas fragmentados, sobre os gestos e os tiques que, invariavelmente, acompanham um diálogo ou uma informação e, às vezes, ampliam, modificam ou contextualizam para além das frases ditas e dos sentidos que se deseja expressar.

Os trabalhos de formação ${ }^{7}$, estudos e pesquisas do grupo se abrem em três grandes linhas, todas relacionadas com a problemática da formação do indivíduo e da individualidade no Brasil urbano contemporâneo. De um lado, encontram-se os trabalhos sobre a discussão da relação entre o processo de morte e do morrer e o sentimento
6. O Grem publica a Revista Brasileira de Sociologia da Emoção-RBSE, revista online, desde o ano de 2002, encontrada no endereço eletrônico: <http:// www.cchla.ufpb.br/ rbse/Index.html>. Hoje, no seu 12 응 ano de existência e com mais de trinta números publicados, continua a ser a primeira e principal publicação no país a lidar, especificamente, com as ciências sociais das emoções. Oferece uma

vitrine do crescente interesse pelas áreas de antropologia e sociologia das emoções, com abertura para áreas correlatas como psicologia, administração, história social, que lidam com as emoções, ampliando o esforço de publicação, visibilidade e consolidação deste campo disciplinar. Desde o seu primeiro número, vem se esforçando na publicação não só de autores nacionais, mas reunindo autores internacionais e, principalmente, latino-americanos, que lidam direta ou indiretamente com a temática.

7. De onde têm saído inúmeros trabalhos de orientação graduada e pósgraduada, como um dos aportes mais significativos 
de luto no Brasil urbano; de outro lado, as questões sobre a imagem e a problemática das emoções; e, por fim, os trabalhos relacionados à questão da relação entre os medos e a cidade, e os processos de confiança e desconfiança que medram os códigos societários de ação: como a vergonha, a traição, a humilhação, o ressentimento e ainda a compreensão social e cultural relacionadas às amizades, ao amor, à paixão e às redes de solidariedade que fundam e dão fundamento à construção e à constituição do social.

A primeira grande linha de pesquisas do grupo, tem trabalhado a relação entre luto e formas de sociabilidade no Brasil urbano contemporâneo. Busca compreender as mudanças e as permanências, os conflitos e as ambivalências nos modos de vida e no imaginário urbano brasileiro, a partir dos anos de 1970. Tem por referência o processo de individualização e individualismo que vêm se processando no Brasil atual.

Esta grande linha de pesquisa vem realizando um balanço do processo de formação e reestruturação vivida pela sociedade brasileira a partir do século XIX aos dias atuais, detendo-se, principalmente, nos últimos 50 anos. A partir de uma releitura aproximativa das obras de Norbert Elias, Georg Simmel e Marcel Mauss, busca compreender a relação entre as alterações na estrutura social e as mudanças nas emoções dos indivíduos e os processos sociais envolvidos na difusão e na recriação contínua dos novos modelos comportamentais que refluem sobre as formas originais de expressão do sentimento, na sociabilidade urbana brasileira.

Procura entender, de um lado, os novos e os velhos suportes que parecem debater-se, de forma ambivalente e ambígua, nas atitudes e nos modos de vida atual dos brasileiros; de outro, busca compreender os mecanismos da ambivalência e da ambiguidade que permitem a estes homens e mulheres viverem esse processo como um sentimento moral em fragmentação, tornando-os mais solitários e, de forma concomitante, em acelerado caminho de individualização.

Quais as formas pessoais e sociais experimentadas na situação limiar do luto, e que instâncias e debates, internos e externos, asseguram aos atores envolvidos se ajustarem aos ritmos da cultura e da organização social local e nacional? Quais os mecanismos que se delineiam como fomentadores e realimentadores dos processos culturais e sociais, na nova reconfiguração da relação entre os indivíduos e a sociedade no país? Até que ponto eles permitem compreender os movimentos de reafirmação do societário instituído como lugar de pertencimento e desilusão, isto é, sempre movendo-se sob novas roupagens e significados e, ao mesmo tempo, em contínua instituição? Essas são questões compreensivas que perpassam as análises e indagações do autor sobre a fundação e a formulação de novas etiquetas e de novas agendas comportamentais, e sobre o processo de continuidade a elas simultâneo, dentro de uma lógica 
de estruturação tradicionalmente satisfeita no país, embora vivida como descontinuidade e com grande sofrimento social e pessoal no cotidiano das interações (Koury, $2003 ; 2005 a)^{8}$.

Outro campo analítico trabalhado pelo Grem busca um aprofundamento das relações entre imagem, memória e as formas de sociabilidade. No âmbito dessas relações, evidencia, principalmente, a análise crítica da fotografia e de suas relações com a problemática dos sentimentos, da memória e dos estados liminares, procurando discutir e compreender a questão sempre tensa da relação entre objetividade e subjetividade na análise da cultura e do social.

Os estudos resultantes deste campo analítico visam, enfim, a construção de importantes passarelas entre a antropologia e a sociologia das emoções e a antropologia e a sociologia da imagem e do visual. As discussões levadas pela antropologia e pela sociologia da imagem e do visual e pela antropologia e sociologia das emoções no Brasil têm dado ênfase e um suporte fundamental, sem dúvida, para o aprofundamento das pesquisas e dos estudos da relação entre processos de subjetividade e de sociabilidade no Brasil contemporâneo, e ajudado a traçar as tênues fronteiras entre as duas especialidades, contribuindo para assegurar um quadro amplo de interdisciplinaridade, como fundamento básico de ampliação e suporte nas áreas em questão ${ }^{9}$.

Os estudos sobre os medos e a cidade, desenvolvidos no grupo de pesquisa, são exemplos das discussões sobre as relações entre processos de subjetividade e sociabilidade acima mencionados. A problemática dos medos e da cidade começa a ser desenvolvida no Grem, de forma mais sistemática, a partir de 2001, quando retoma as discussões que o grupo de pesquisa vinha desenvolvendo desde os anos de 1980 sobre a formação do homem comum no Brasil ${ }^{10}$ e sobre a constituição de um discurso modernizador e disciplinador da cidade (Koury, 1986; 1988; 1993). Assim como o desenvolvimento de pesquisas sobre a questão da pobreza, da violência e da cidadania no Brasil, e sobre os sentidos da categoria de pertença e sua relação com as noções de confiança, lealdade, medo de traição; ou da insegurança individual e as redes vinculares que dão sustentação e base de apoio à sociabilidade.

A agenda de pesquisa do Grem organiza-se, assim, desde o final dos anos de 1980, através de uma série de estudos, debates e investigações sobre a emoção medo no meio urbano contemporâneo brasileiro e, especialmente, paraibano ${ }^{11}$. Essas séries têm se detido, particularmente, na categoria dos medos corriqueiros, que procura enfatizar os diversos enfrentamentos do homem comum no seu vivenciar cotidiano. Essa agenda, através de uma leitura simmeliana do segredo e das formas de sociabilidade e constituição do indivíduo na modernidade ocidental, parte das hipóteses
8. Nessa temática, várias monografias e dissertações, orientadas pelo autor, foram desenvolvidas e concluídas no âmbito do Grem, outras ainda se encontram em processo de orientação. Entre as concluídas, cabe destacar os trabalhos de Santos (2000); Dantas (2001); Santos (2001); Santos (2002), entre outras.

9. Na temática relativa às relações entre imagem, memória e as formas de sociabilidade, vários trabalhos de monografia e dissertações também foram orientados e concluídos. Com destaque para os trabalhos de Barreto (1996); Lira (1997); Farias Jr. (2001); Souza (2001); Correia (2002), entre outros.

10. Neste artigo emprega-se o conceito de homem comum para dar conta dos indivíduos desprovidos de cargos e representações sociais, religiosas, políticas, econômicas, associativas, estéticas e artísticas. Em outras palavras, através da compreensão dos processos que configuram o homem ordinário imerso em seu cotidiano, buscase entender as maneiras como 
os indivíduos se reapropriam dos elementos sociais e culturais de uma sociabilidade dada - no caso a brasileira, em seus diversos modos regionais e locais - e por onde, no interior de situações corriqueiras por eles vivenciadas, de forma direta ou indireta,

são construídas

e remodeladas continuamente as experiências. Segundo Certeau (1990), na atividade do reuso e das apropriações encontra-se uma bom número de oportunidades para as pessoas comuns vivenciarem, aceitarem, modificarem ou subverterem os códigos hegemônicos a eles impostos.

11. Vários trabalhos de monografia e dissertação foram realizados a partir desta problemática. Cabe aqui destacar, entre outros, Oliveira (1999); Silva (2003); Souza (2003); Souza (2004); Silva (2004); Cavalcante Filho (2005); Almeida (2005); Coelho (2006); Silva (2006). Alguns foram transformados em artigos que compuseram a coletânea organizada por Koury (2005b), que engloba uma série de trabalhos de monografias e dissertações orientadas no quadro do Grem sobre o tema. de que a emoção medo é uma construção social significativa para a análise do social, e de que em toda e qualquer forma de sociabilidade o medo se encontra presente como uma das principais forças organizadoras do social e da cultura (Koury, 2002).

O fenômeno dos medos e, por extensão, dos medos corriqueiros, coloca-se como essencial para se pensar os embates de configuração e os processos de sociabilidades e de formação dos instrumentos da ordem e da desordem em um tempo e espaço singular, que desenham dialeticamente a ação dos indivíduos e dos grupos em relação entre si (Koury, 2008). Esses processos compreendem um jogo permanente de manutenção, de conformação e de transformação de ações e propostas sociais e individuais, realizados enquanto redes de conflito, que informam e formulam um social singular.

A análise sobre a categoria sofrimento social é outra temática emergente nos estudos e nas pesquisas do Grem. Koury (2007; 2010; 2012) tem desenvolvido estudos que abordam a questão do sofrimento social e os discursos de naturalização e da banalização da problemática na sociedade brasileira; e, junto com Marcela Zamboni e Simone Brito têm discutido a expressão dos sentimentos de inevitabilidade e de indiferença nos discursos e nas narrativas sobre a problemática da violência e de situações limites, no social brasileiro contemporâneo, principalmente no meio urbano (Koury, Zamboni \& Brito, 2010). Novas interfaces nesta temática têm sido abertas: Simone Brito, por exemplo, tem aberto linhas de pesquisa para pensar a moralidade no interior da teoria crítica (Brito, 2007; 2012) e a relação entre esporte (futebol) e moral (Brito, 2011).

Nesta última, procura refletir a construção social da normatividade e os modos de justificação no debate sobre tecnologias de monitoramento, e analisar os processos de construção social da moralidade a partir do debate sobre o uso de tecnologias de monitoramento no futebol. O objetivo principal desta reflexão é entender, a partir do debate sobre a adequação, correção e justiça do uso do vídeo para auxiliar nas decisões dos juízes de futebol, os argumentos, os recursos normativos e as necessidades pragmáticas utilizadas para o estabelecimento de modos de justificação e construção de valores no mundo do futebol.

Marcela Zamboni (2010), por seu lado, tem trabalhado as relações entre as emoções e o conceito de confiança na construção amorosa, e vem desenvolvendo estudos e pesquisas sobre o lugar da desconfiança e da infidelidade nos fóruns criminais, tendo como objeto os homicídios entre cônjuges, sob a lente dos operadores jurídicos. O seu objetivo é avaliar a importância da infidelidade como elemento indispensável à quebra de confiança nas relações afetivo-conjugais: analisa os processos e a performance do tribunal do júri e dos operadores jurídicos (promotor público, defensor 
público (advogado dativo) ou advogado de defesa e juiz, nos momentos de defesa e de acusação da(o) ré(u), nos casos de homicídios praticados entre cônjuges no Fórum Criminal de João Pessoa, estado da Paraíba. Atualmente, procura discutir a atuação dos operadores jurídicos quando julgam casos de homicídios passionais perpetrados contra as mulheres, a partir de um estudo comparativo entre o Brasil e a Inglaterra.

Em outra direção, Anderson Moebus Retondar (2007; 2008; 2008a), sempre no âmbito do Grem, tem organizado a linha de pesquisa sobre as relações entre emoções e consumo. Atualmente vem desenvolvendo um projeto que discute as relações entre o ético e o político na experiência de consumo na sociedade contemporânea. Parte da constatação de que o debate atual sobre o significado das práticas de consumo na sociedade contemporânea vem elaborando novas questões, entre as quais é possível destacar a ideia do consumo político, o que, segundo o autor, enfatiza a experiência de um consumidor mais consciente de sua atividade de consumo, em meio a um processo de interação entre consumidor/objeto/sociedade que o transformaria em agente ativo no processo social.

A tensão entre os apelos sistêmicos da publicidade e dos megagrupos da indústria de alimentos parece deparar-se com uma cada vez maior reatividade de grupos e indivíduos preocupados com questões relativas não apenas à saúde individual, mas também a questões que se ampliam para a sociedade em geral como sustentabilidade e consumo ético. Nessa discussão, a ideia de um consumo politizado revelaria não apenas a não passividade do consumidor, mas, do ponto de vista da teoria social mais geral, a possibilidade de interação entre agência e estrutura, mediada agora por práticas consumistas.

Retondar (2009; 2012), ao partir desta ideia, coloca como marco de discussão a necessidade de refletir sobre os sentidos e o caráter deste tipo de experiência de consumo para os sujeitos que as praticam, tentando perceber, a partir de suas práticas e representações, em que medida estas revelam, de fato, uma dimensão de ação política, buscando uma intervenção no sistema social a partir do consumo ou, de outro modo, se o seu apelo se constitui no sentido de uma ética individual, marcada por demandas e obrigações que se esgotam em si mesmas.

É importante ressaltar que atualmente o Grem tem se ocupado com a ampliação da rede de compartilhamentos dos pesquisadores a ele associados. Nesse caminho tem aberto espaço para pesquisadores atuantes em outras instituições de ensino superior e grupos de pesquisa no país, que desenvolvem trabalhos com ênfase na antropologia e na sociologia das emoções. Nessa direção, tem aberto espaço para pesquisadores associados externos, como Marconi Pequeno, da pós-graduação em filosofia da UFPB; 
12. Roberta Bivar Carneiro Campos é pesquisadora e, também, vicelíder do Núcleo de Pesquisa sobre Religiões Populares do Programa de Pós-Graduação em Antropologia da Universidade Federal de Pernambuco. Tem trabalhado na área de antropologia, com ênfase em antropologia das emoções, atuando principalmente nos seguintes temas: religião, cultura e identidade, emoções, teoria antropológica, corpo e sociedade e sofrimento social.
Roberta Bivar Carneiro Campos, da pós-graduação em antropologia da UFPE ${ }^{12}$; Claudia Barcellos Rezende, da pós-graduação em ciências sociais da Uerj; Marieze Torres do Centro de Recursos Humanos da UFPB; Francisca Verônica Cavalcante, da pós-graduação em antropologia da UFPI; Maria Cristina Rocha Barreto, professora da pós da Uern; e Luiz Gustavo Pereira de Souza Correia, da pós da UFS.

O objetivo é ampliar o intercâmbio entre os grupos de pesquisa em antropologia e sociologia das emoções no país, através de um diálogo mais de perto com os seus pesquisadores, além do desenvolvimento de projetos comuns e criação de alternativas para a consolidação da área e dos esforços nessa direção desenvolvidos em cada instituição de ensino superior e no país.

\section{O Grupo de Pesquisa Transformações da Intimidade}

Outro grupo de pesquisa que tem tido o compromisso com o processo de desenvolvimento do campo disciplinar da antropologia das emoções no Brasil, desde 1998, é o Grupo de Pesquisa Transformações da Intimidade sob a liderança de Maria Claudia Coelho e Claudia Barcellos Rezende, da Universidade Estadual do Rio de Janeiro (Uerj). Este grupo tem por objetivo o exame das formações da subjetividade constitutivas do mundo contemporâneo, e o refletir sobre as formas de articulação entre os níveis micro e macro da vida social a partir da análise dos limites e das possibilidades de construção das esferas tradicionalmente entendidas como restritas à experiência individual, tais como a subjetividade, o corpo e as emoções.

A partir de meados dos anos de 1990, Maria Claudia Coelho vem pesquisando no campo da antropologia das emoções. O seu trabalho traz uma importante contribuição para a análise compreensiva da subjetividade no mundo contemporâneo e, em especial, para o estudo da dádiva, ao debater a relação entre os conceitos de dádiva e de emoções (Coelho, 2003; 2006). Neste debate ela procura compreender os princípios, as normas e as regras que norteiam a troca de presentes, e discute a dádiva como uma tática usada para a construção de identidades e de demonstração das emoções na sociedade brasileira contemporânea, com destaque para a carioca. Outra linha trabalhada por Coelho (2006a; 2010; 2012) é a questão do gênero, onde faz um entrecruzamento entre os conceitos de emoções e violência através de relatos e experiências de vitimização entre mulheres.

No final da década de 1990, Claudia Barcellos Rezende adota a antropologia das emoções como linha de pesquisa específica para estudar a problemática da amizade. Em sua pesquisa, faz uma análise da emoção amizade entre cariocas e londrinos, na tentativa de comparar e identificar os modos de vida e a organizações emocional e social no Brasil e na Inglaterra. 
O seu livro Os significados da amizade (Rezende, 2002) pode ser considerado como o seu principal trabalho. É um estudo comparativo sobre a amizade em dois contextos culturais bastante diferenciados: as cidades do Rio de Janeiro e a cidade de Londres. Em sua pesquisa, a autora procura compreender como a linguagem da amizade lança luz sobre o modo de construir e reforçar hierarquias sociais, a partir de uma abordagem no interior da antropologia das emoções.

Rezende aprofunda os tipos de sociabilidade que serviram como suporte formativo e imaginário para as noções de amizade existentes em cada uma das culturas estudadas, e realiza para tal uma incursão no campo teórico da antropologia das emoções, produzindo uma etnografia sobre os significados e as práticas sociais e culturais da amizade e suas relações com os conceitos de classe, de gênero e, no caso brasileiro, além das relações anteriormente citadas, sobre a problemática interétnica e a questão racial.

Em outro trabalho, intitulado Mágoas de amizade, também baseado na pesquisa sobre os significados da amizade, Rezende (2002a) segue, uma vez mais, o caminho da antropologia das emoções e, através dela, analisa a recorrência das categorias de grosseria e de ofensa no discurso sobre amizade em um grupo de ingleses de camadas médias, moradores da cidade de Londres.

Contribuições importantes para a consolidação da área disciplinar da antropologia, bem como da sociologia das emoções, no Brasil. Os estudos de Rezende denotam afinidades com autores clássicos como Georg Simmel, Max Weber, Norbert Elias, Michel Foucault e Pierre Bourdieu, e discute os precursores brasileiros da antropologia e da sociologia das emoções, como Roberto Da Matta e Gilberto Velho, entre outros, que procuram explicitar a emergência de uma subjetividade singular vinculada às mudanças históricas e culturais no mundo ocidental e no Brasil.

Os estudos de Rezende, deste modo, têm ajudado a elaboração de uma síntese importante e necessária dos pressupostos teórico-metodológicos que norteiam a configuração analítica no interior da uma proposta das ciências sociais das emoções no Brasil, principalmente no interior da disciplina antropologia. Seus trabalhos também passam pelo estudo da problemática dos sentidos da cordialidade, presente no pensamento social brasileiro dos últimos cem anos (Rezende, 2003) e sobre a questão da identidade nacional (Rezende, 2006; 2008).

Atualmente, Claudia Barcellos Rezende (2011; 2011a; 2012) vem trabalhando as relações entre emoções, corpo e moral, tendo as experiências com gestantes e suas representações sobre o processo de gravidez e gestão como universo de análise. Nesta nova problemática, tem explorado como as gestantes propõem formas de lidar com 
o corpo grávido, articuladas a sentimentos vistos e sentidos como adequados. Nesse sentido, argumenta que há uma proposta educativa em torno do corpo grávido, como busca de melhor controlá-lo, e que nesse processo são recorrentes as emoções de medo e ansiedade. Discute os valores morais dados à maternidade na sociedade brasileira e, especificamente, carioca, de camadas médias, e revela as tensões entre os sentimentos da gravidez, em relação à percepção da mulher como sujeito moral, seja no interior dos grupos de apoio entre mulheres grávidas, ou através das representações da gravidez na mídia.

\section{O Grupo de Pesquisa Cultura, Sociabilidades e Sensibilidades Urbanas}

Um terceiro grupo de pesquisa importante na definição das fronteiras e em busca da consolidação da antropologia e sociologia das emoções no Brasil emerge a partir de 2010, na Universidade Federal da Bahia. Este grupo, liderado por Marieze Rosa Torres e Patrícia Carla Smith Galvão, passou a desenvolver um esforço na direção de um fortalecimento do campo disciplinar ligado à sociologia das emoções. O grupo é composto por duas linhas de pesquisa, a primeira - "Configurações urbanas: identidade, conflito e sociabilidade" - tem por objetivo a compreensão das subjetividades dos sujeitos sociais nas cidades baianas, considerando as suas estratégias de convivência e sociabilidade, a partir de dois eixos temáticos: o primeiro busca dar voz aos "tipos" locais, que habitam o lugar e representam a sua identidade e a sua cultura, destacando as suas manifestações de resistência e de afirmação; o segundo foca os segmentos cuja condição social os torna vulnerável à discriminação e violação de direitos. A segunda linha do grupo - "Emoções, indivíduo e sociedade" - objetiva promover debates sobre as teorias socioantropológicas de emoções, desenvolver estudos sobre emoções no âmbito das sociedades brasileira e baiana, e investir na formação de estudantes de ciências sociais, despertando-lhes o interesse no desenvolvimento de trabalhos acadêmicos que incorporem emoções como variável explicativa para a compreensão dos processos e fenômenos sociais.

Os estudos decorrentes das linhas de pesquisa que integram o grupo Cultura, Sociabilidades e Sensibilidades Urbanas abarcam a compreensão das maneiras de organização da vida, os padrões de sociabilidade, os conflitos e as disputas, assim como as afinidades e aproximações que animam as relações entre sujeitos. Uma dimensão fundamental que caracteriza as pesquisas desenvolvidas pelo grupo é a incorporação da subjetividade dos sujeitos na análise dos fenômenos e processos sociais que estuda. A incorporação da esfera dos sentimentos inclui as formas de sentir e de expressar as emoções, e as percepções distintas, conflitantes ou convergentes desses sujeitos sociais. Os estudos desenvolvidos no interior do grupo de pesquisa concentram-se na sociedade brasileira e, especialmente, na sociedade baiana e soteropolitana. 
Torres (2009) concluiu o seu doutoramento na Universidade Federal da Bahia, com a defesa da tese "Hóspedes incômodas? Emoções na sociologia norte-americana", contribuindo para as discussões teórico-metodológicas iniciadas desde os anos de 1990 no cenário brasileiro. Examina a discussão teórica sobre as emoções no âmbito da produção sociológica norte-americana recente, através de algumas posições e polarizações recorrentes, que demarcam as fronteiras entre escolas de pensamento de perspectivas distintas de análise das emoções de um ponto de vista sociológico.

As discussões teóricas e as polarizações são abordadas no âmbito dos debates travados entre as posições caracterizadas como biossocial, representada por Theodore Kemper e Jonathan Turner, e a construtivista por Arlie Hochschild, Susan Shott e Steven Gordon. No debate, as divergências dizem respeito à própria definição de emoções e de seus elementos componentes ou causais. Trata-se de saber se as emoções são inatas e universais, pré-fixadas no organismo e distinguidas por certos hormônios, ou se as emoções são produtos da cultura e sua definição um produto da interpretação do ator.

Essas discordâncias, transpostas para as proposições de articulação dos níveis macro e micro de análise, contrastam a posição construtivista de que a vida social é organizada por regras de sentimento e vocabulários de emoções, com a posição biossocial que propõe os conceitos de poder e status como dimensões estruturantes, universais, fisiologicamente correlacionadas, de todas as relações sociais humanas.

A tese considera que as divergências tornadas explícitas nesses debates, retomam e atualizam questões discutidas pelos pragmatistas William James e John Dewey. 0 exame, por fim, conclui que uma análise sociológica e integradora das emoções em seus nexos com o corpo ainda se encontra em movimento, embora já se configurem no seu interior formas assentadas de caminhos teórico-metodológicos em processo de aprofundamento e consolidação.

O Grupo de Pesquisa Cultura, Sociabilidades e Sensibilidades Urbanas, por fim, a partir de sua criação, além do trabalho teórico-metodológico no âmbito da sociologia das emoções, vem desenvolvendo trabalhos ligados às problemáticas relacionadas à questão de gênero, das emoções e da sexualidade; sobre juventude e marginalização (Galvão, 2012); sobre conflito e desvio social; sobre formas de organização de vida e pobreza (Galvão, 2012a), entre outros.

Esses três grupos de pesquisa ${ }^{13}$ e seus pesquisadores e estudantes, situados nos estados da Paraíba, Rio de Janeiro e Bahia são, hoje, os grupos que vêm assumindo mais diretamente o processo de consolidação e o desenvolvimento da antropologia e da sociologia das emoções no Brasil ${ }^{14}$. A constituição de novas pontes e vias que viabi-
13. Pode-se incluir um quarto esforço na direção de uma antropologia e uma sociologia das emoções com o trabalho desenvolvido pelo Núcleo de Pesquisa sobre Religiões Populares do Programa de Pós-Graduação em Antropologia da Universidade Federal de Pernambuco pela pesquisadora e vice-líder do núcleo Roberta Bivar Carneiro Campos, que pesquisa a relação entre as emoções e a religiosidade (Campos, 2012).

14. Existe um número crescente de dissertações e teses isoladas defendidas desde 2008, em vários programas de pósgraduação do país, que já apontam a antropologia ou a sociologia das emoções como eixo temático central. 
15. É importante observar que desde o ano de 2008 esses grupos têm desempenhado um papel importante no processo de abertura para criação de redes de compartilhamento na América Latina, principalmente em países como Argentina, México, Chile e Peru, como se verá adiante, principalmente na abertura de grupos de trabalho em congressos e encontros internacionais como a Reunião de Antropólogos do Mercosul (RAM) e da Asociação Latino-Americana de Sociologia (Alas).

16. Os da Associação Nacional de Pesquisa e Pós-Graduação em Ciências Sociais (Anpocs); da Reunião Brasileira de Antropologia (RBA); das Reuniões de Antropólogos do Norte/Nordeste; dos Encontros Norte/Nordeste de Cientistas Sociais (Ciso's).

17. Os da Associação Latino-Americana de Sociologia (Alas) e do Reunión de Antropología del Mercosur (RAM). lizem a consolidação dessas duas áreas disciplinares obrigatória e indiscutivelmente devem partir desses três grupos e do compartilhamento com e entre eles ${ }^{15}$.

\section{A antropologia e a sociologia das emoções em encontros e congressos}

Pelo relato até agora realizado, pode-se notar que a antropologia e a sociologia das emoções apresentam-se, em sua edificação, como campo de conotação interdisciplinar e de grande profusão temática. Nesse processo constitutivo percorrem e fundam interfaces entre campos disciplinares diversos, não apenas no âmbito das ciências sociais, mas também junto à psicologia, a psicanálise, a psiquiatria, a história, a economia, a administração, a arquitetura, a geografia humana, entre outros.

Para este estudo, foi realizado um mapeamento dos diversos temas apresentados em congressos nacionais ${ }^{16}$ e latino-americanos ${ }^{17}$, durante os anos de 2001 a 2012, em um total de 530 trabalhos. Os congressos e encontros analisados tiveram grupos de traba-

\section{QUADRO I}

CONGRESSOS COM GTS EM ANTROPOLOGIA OU SOCIOLOGIA DAS EMOÇÕES OU CORRELATOS E SEUS COORDENADORES (2001-2012)

\begin{tabular}{|c|c|c|c|}
\hline Ano & Congresso & Organizadores & IES Organizadores \\
\hline 2001 & $\mathrm{X}$ Ciso & $\begin{array}{l}\text { Mauro Guilherme Pinheiro Koury } \\
\text { lara Souza }\end{array}$ & $\begin{array}{l}\text { Grem/UFPB } \\
\text { Nams/UFBA }\end{array}$ \\
\hline \multirow{3}{*}{2003} & VIII RAN/NE & $\begin{array}{l}\text { Mauro Guilherme Pinheiro Koury } \\
\text { Maria Cristina Rocha Barreto }\end{array}$ & $\begin{array}{l}\text { Grem/UFPB } \\
\text { Grem/Uern }\end{array}$ \\
\hline & V RAM & $\begin{array}{l}\text { Mauro Guilherme Pinheiro Koury } \\
\text { Luiz Gustavo de Souza Correia }\end{array}$ & $\begin{array}{l}\text { Grem/UFPB } \\
\text { Grem/UFRGS }\end{array}$ \\
\hline & XI Ciso & $\begin{array}{l}\text { Mauro Guilherme Pinheiro Koury } \\
\text { Maria Cristina Rocha Barreto }\end{array}$ & $\begin{array}{l}\text { Grem/UFPB } \\
\text { Grem/Uern }\end{array}$ \\
\hline \multirow{2}{*}{2005} & VI RAM & $\begin{array}{l}\text { Mauro Guilherme Pinheiro Koury } \\
\text { Maria Claudia Coelho }\end{array}$ & $\begin{array}{l}\text { Grem/Uern } \\
\text { GPTI/Uerj }\end{array}$ \\
\hline & XII Ciso & $\begin{array}{l}\text { Mauro Guilherme Pinheiro Koury } \\
\text { Maria Cristina Rocha Barreto }\end{array}$ & $\begin{array}{l}\text { Grem/UFPB } \\
\text { Grem/Uern }\end{array}$ \\
\hline \multirow{2}{*}{2010} & XXXIV Anpocs & $\begin{array}{l}\text { Alexandre Vieira Werneck } \\
\text { Luis Roberto Cardoso de Oliveira }\end{array}$ & Necvu/UFRJ \\
\hline & XXXIV Anpocs & $\begin{array}{l}\text { Maria Claudia Coelho } \\
\text { Cynthia Andersen Sarti }\end{array}$ & $\begin{array}{r}\text { GPTI/Uerj } \\
\text { Unifesp }\end{array}$ \\
\hline \multirow{3}{*}{2011} & Alas-Recife & $\begin{array}{l}\text { Mauro Guilherme Pinheiro Koury } \\
\text { Adrián Scribano } \\
\text { Rogelio Luna Zamora } \\
\text { Zandra Pedraza }\end{array}$ & $\begin{array}{l}\text { Grem/UFPB } \\
\text { Argentina } \\
\text { México } \\
\text { Venezuela }\end{array}$ \\
\hline & XXXV Anpocs & $\begin{array}{l}\text { Maria Claudia Coelho } \\
\text { Cynthia Andersen Sarti }\end{array}$ & $\begin{array}{l}\text { GPTI/Uerj } \\
\text { Unifesp }\end{array}$ \\
\hline & XXXV Anpocs & $\begin{array}{l}\text { Alexandre Vieira Werneck } \\
\text { Luis Roberto Cardoso de Oliveira }\end{array}$ & $\begin{array}{l}\text { Necvu/UFRJ } \\
\text { UnB }\end{array}$ \\
\hline 2012 & XV Ciso & $\begin{array}{l}\text { Mauro Guilherme Pinheiro Koury } \\
\text { Marieze Rosa Torres }\end{array}$ & $\begin{array}{l}\text { Grem/UFPB } \\
\text { cSSU/UFBA }\end{array}$ \\
\hline
\end{tabular}

Fonte: Grem - Linha de Pesquisa "História das ciências sociais". 
Iho (GT) sobre a temática antropologia e sociologia das emoções, ou incluíram temas próximos em seus GTs. Foram analisados os X, XI, XII e XV Ciso's, acontecidos nos anos de 2001, 2003, 2005 e 2012; os V e VI RAMs, realizados em 2003 e 2005; o VIII RAN/ NE, em 2003; os encontros da Anpocs dos anos de 2010 e 2011; e o Congresso da Alas, de 2011 (Quadro I).

Foi durante o X Ciso - Encontro Norte/Nordeste de Ciências Sociais, no ano de 2001, que surgiu no cenário acadêmico dos grupos de trabalho dos congressos e encontros nacionais e latino-americanos o primeiro GT sobre o tema antropologia e sociologia das emoções. Este GT teve como área de discussão, de modo explícito, a sociologia das emoções. O X Ciso aconteceu na UFBA e o GT Sociologia das Emoções teve como coordenadores Mauro Guilherme Pinheiro Koury, líder do Grupo de Pesquisa em Antropologia e Sociologia das Emoções da UFPB e lara Souza, do Núcleo de Antropologia Médica e Saúde da UFBA, como pode ser observado no Quadro I.

Nesse grupo de trabalho foram apresentadas 31 comunicações. Dessas, 26\% (8) foram trabalhos ligados à área de emoções/saúde/corpo; 13\% (4), ligados à teoria das emoções; e 13\% (4) ao luto e às representações da morte e do morrer. Estas três problemáticas foram responsáveis por $52 \%$ (16) das comunicações apresentadas no grupo de trabalho.

As demais $48 \%$ das comunicações apresentadas percorreram temas ligados à arte, trabalho, religiosidade, política, modos de vida, mídia, medos e violência e identidade. Todas elas traziam a discussão da subjetividade para a análise do social e da cultura ${ }^{18}$, mas não necessariamente enfatizaram a antropologia ou a sociologia das emoções em suas análises (Quadro 2).

Esses mesmo temas, acrescidos de outros, surgem nos demais congressos e encontros analisados, onde a questão da subjetividade aparece como o chamariz principal para os grupos de trabalho que têm a categoria emoções em suas chamadas. Essa profusão de temas vêm se repetindo ano após ano (Quadro 3), impelindo à necessidade de que as discussões sobre as fronteiras, mesmo que tênues, de um novo campo disciplinar aconteçam: o que se tem feito até agora de modo tímido e pouco aprofundado. A discussão sobre fronteiras, desse modo, torna-se um imperativo para que os pesquisadores, que se debru-

\section{QUADRO 2}

TEMAS DAS COMUNICAÇÕES APRESENTADA NO GT SOCIOLOGIA DAS EMOÇÕES NO X CISO (2001)

\begin{tabular}{|l|c|c|}
\hline \multicolumn{1}{|c|}{ Temas } & n. - & $\%$ \\
\hline Corpo/saúde & 8 & 26,0 \\
\hline Teria das emoções & 4 & 13,0 \\
\hline Luto e representações da morte & 4 & 13,0 \\
\hline Religiosidade & 3 & 9,6 \\
\hline Mídia & 3 & 9,6 \\
\hline Medos/violência & 2 & 6,4 \\
\hline Identidade & 2 & 6,4 \\
\hline Arte & 2 & 6,4 \\
\hline Sociabilidade e modos de vida & 1 & 3,2 \\
\hline Trabalho e emoções & 1 & 3,2 \\
\hline Política e emoções & 1 & 3,2 \\
\hline Total & 31 & 100,0 \\
\hline Fonte: Grem - Linha de Pesquisa "História das ciências \\
sociais".
\end{tabular}

18. A possibilidade de discutir a questão da subjetividade em um congresso de cientistas sociais foi, segundo a maior parte dos congressistas que enviaram trabalho para o GT sociologia das emoções do X Ciso, a atração principal, por se tratar então de novidade temática. 
QUADRO 3

TEMAS DAS COMUNICAÇÕES NOS GTS ANTROPOLOGIA E SOCIOLOGIA DAS EMOÇÕES POR ANO (2001 A 2012)

\begin{tabular}{|c|c|c|c|c|c|c|c|c|c|c|c|c|c|c|}
\hline \multirow{2}{*}{ Temas/Ano } & \multicolumn{2}{|c|}{2001} & \multicolumn{2}{|c|}{2003} & \multicolumn{2}{|c|}{2005} & \multicolumn{2}{|c|}{2010} & \multicolumn{2}{|c|}{2011} & \multicolumn{2}{|c|}{2012} & \multicolumn{2}{|c|}{ Total } \\
\hline & n.. & $\%$ & ก. $\stackrel{\circ}{ }$ & $\%$ & n.. & $\%$ & $\mathrm{n} . \stackrel{\circ}{0}$ & $\%$ & n.. & $\%$ & $\mathrm{n} . \stackrel{\circ}{0}$ & $\%$ & n.. & $\%$ \\
\hline Sociabilidade e modos de vida & 1 & 3,2 & 4 & 7,1 & 5 & 14,7 & 3 & 3,5 & 59 & 27,3 & 27 & 25,2 & 99 & 18,7 \\
\hline Corpo e saúde & 8 & 26 & - & - & - & - & 19 & 22,1 & 28 & 13 & 22 & 20,6 & 77 & 14,5 \\
\hline Identidade & 2 & 6,4 & 1 & 1,8 & 2 & 5,9 & 4 & 4,6 & 37 & 17,1 & 5 & 4,7 & 51 & 9,7 \\
\hline Gênero e envelhecimento & - & - & 14 & 25 & 2 & 5,9 & 5 & 5,8 & 17 & 7,9 & 4 & 3,7 & 42 & 7,9 \\
\hline Medos e violência & 2 & 6,4 & 19 & 34 & 4 & 11,7 & 5 & 5,8 & 3 & 1,4 & 5 & 4,7 & 38 & 7,2 \\
\hline Controle social/Práticas disciplinares & - & - & 1 & 1,8 & 1 & 2,9 & 10 & 11,6 & 21 & 9,7 & 5 & 4,7 & 38 & 7,2 \\
\hline Moralidade e emoções & - & - & - & - & - & - & 30 & 35 & 4 & 1,9 & - & - & 34 & 6,4 \\
\hline Religiosidade & 3 & 9,6 & 5 & 9 & 2 & 5,9 & 7 & 8,1 & 2 & 0,9 & 11 & 10,3 & 30 & 5,7 \\
\hline Luto e representações da morte & 4 & 13 & 2 & 3,5 & 6 & 17,7 & 2 & 2,3 & 8 & 3,7 & 8 & 7,5 & 30 & 5,7 \\
\hline Teoria das emoções & 4 & 13 & 2 & 3,5 & 2 & 5,9 & - & - & 15 & 6,9 & 3 & 2,8 & 26 & 4,9 \\
\hline Arte & 2 & 6,4 & 6 & 10,7 & 6 & 17,7 & - & - & 2 & 0,9 & 7 & 6,5 & 23 & 4,3 \\
\hline Mídia & 3 & 9,6 & 1 & 1,8 & 2 & 5,9 & - & - & 8 & 3,7 & 2 & 1,8 & 16 & 3,0 \\
\hline Trabalho e emoções & 1 & 3,2 & 1 & 1,8 & 1 & 2,9 & 1 & 1,2 & 4 & 1,9 & 5 & 4,7 & 13 & 2,4 \\
\hline Política e emoções & 1 & 3,2 & - & - & 1 & 2,9 & - & - & 8 & 3,7 & 3 & 2,8 & 13 & 2,4 \\
\hline Total & 31 & 100,0 & 56 & 100,0 & 34 & 100,0 & 86 & 100,0 & 216 & 100,0 & 107 & 100,0 & 530 & 100,0 \\
\hline
\end{tabular}

Fonte: Grem - Linha de Pesquisa "História das ciências sociais".

19. E, pode-se dizer, também na América Latina é novidade.

\section{No Quadro 4} a América Latina contempla a categoria "Outros países", com 16\% das comunicações apresentadas nos encontros e congressos aqui analisados. çam de uma maneira mais direta e constante sobre a antropologia e a sociologia das emoções, encaminhem a questão nos próximos encontros e congressos, de modo a enraizar mais e mais um ethos disciplinar aos estudos sobre as emoções.

A partir do Quadro 3, a seguir, é possível visualizar, de um lado, que o campo acadêmico que envolve a antropologia e a sociologia das emoções, tem despertado interesse crescente por parte dos pesquisadores e estudantes graduados e pós-graduados no Brasil; de outro, contudo, enfatiza a ideia de que é um campo disciplinar ainda em construção, precisando de uma atuação mais consistente dos pesquisadores que nele atuam no sentido de delimitar melhor as fronteiras desta área disciplinar no Brasil ${ }^{19}$. Para tal, é necessário um maior esforço na promoção de discussões teórico-metodológicas sobre o significado da categoria emoções para a análise antropológica e sociológica, objetivando a consolidação das mesmas. As ciências sociais das emoções, sobretudo a antropologia e a sociologia das emoções, são áreas ainda bastante frágeis, necessitando um esforço conjunto forte e direcionado na definição, delimitação e consolidação de sua esfera de atuação e representação acadêmica.

Como se pode ver na Quadro 4, o interesse de pesquisadores e estudantes pela antropologia e pela sociologia das emoções se expande e cresce por todas as regiões do país e pela América Latina ${ }^{20}$, dando significado à sua importância potencial nas ciências sociais brasileiras e latino-americanas. No Quadro 5, por outro lado, nota-se uma distribuição dos interesses na área por região do Brasil: assim, por exemplo, a Região Nordeste concentra o maior número das comunicações e trabalhos apresenta- 
dos na relação entre emoções, cultura e sociedade nos encontros e congressos analisados, no total de $40,2 \%$, e a Região Sudeste fica em segundo, com $27,7 \%$ dos trabalhos e comunicações expostos.

As duas regiões assinaladas perfazem o total de $67,9 \%$ das comunicações aceitas e apresentadas nos grupos de trabalho sobre antropologia e sociologia das emoções nos congressos e encontro mapeados neste trabalho. As demais regiões Norte, Centro-Oeste e Sul -, aparecem com um percentual de $16,1 \%$ dos trabalhos aceitos e apresentados nos grupos de pesquisa que lidam com emoções.

Os Quadros 4 e 5 mostram que o trabalho para ampliação e consolidação dos campos disciplinares da antropologia e da sociologia das emoções no Brasil, e por extensão, na América Latina, tem de levar em conta o estado da arte desenvolvido pelas regiões Nordeste e Sudeste nestes quase 20 anos de trabalho. Daí a importância dessas regiões assumirem para si, junto às demais regiões e países, a agenda de impulsão para as ações com vistas à delimitação, consolidação e ampliação das discussões e visibilidade deste campo disciplinar, tanto no país, quanto na América Latina.

\section{QUADRO 5}

PARTICIPANTES EM GTS ANTROPOLOGIA E SOCIOLOGIA DAS EMOÇÕES POR REGIÃO E PAÍSES

\begin{tabular}{|l|r|r|}
\hline \multicolumn{1}{|c|}{ Região } & n. & \multicolumn{1}{c|}{$\%$} \\
\hline Norte & 21 & 4,0 \\
\hline Nordeste & 213 & 40,2 \\
\hline Centro-Oeste & 25 & 4,7 \\
\hline Sudeste & 147 & 27,7 \\
\hline Sul & 39 & 7,4 \\
\hline Brasil & 445 & 84,0 \\
\hline Outros países & 85 & 16,0 \\
\hline Total Geral & 530 & 100,0 \\
\hline Fonte: Grem - Linha de Pesquisa “História
\end{tabular}
das ciências sociais".
É necessário que os pesquisadores e grupos de pesquisa atuantes na área tragam para si o debate necessário sobre o alargamento destes campos disciplinares, discutindo o estabelecimento de fronteiras porosas e passíveis de movimentação e elasticidade no seu interior para, deste modo, fortalecer os processos já abertos de consolidação da área, e de ampliação dos interesses de novos pesquisadores e estudantes para os campos disciplinares de emoções, cultura e sociedade. 
21. Além dos já citados no Brasil, objeto desse trabalho, na Argentina surge em 2011 o Centro de Investigaciones y Estudios Sociológicos (Cies), sob a liderança de Adrián Scribano, que mantém uma revista online Revista Latinoamericana sobre Cuerpos, Emociones y Sociedad - Relaces $<w w w$. relaces.com.ar>, entre outros.
O trabalho coletivo em prol do desenvolvimento das áreas disciplinares da antropologia e da sociologia das emoções no interior da academia brasileira (e latino-americana) nesses últimos 20 anos, como se pode ver no desenvolvimento deste artigo, tem apresentado resultados positivos, quer no interesse crescente de pesquisadores e estudantes, seja pela ampliação dos fóruns de debate e grupos e centros de pesqui$s^{21}$, ou pela delimitação de linhas de pesquisa no interior de departamentos e cursos, quer pela oferta regular de disciplinas em sociologia e antropologia das emoções nos cursos de graduação e pós-graduação no país. Nota-se ainda um grande esforço na composição de dossiês em revistas acadêmicas direcionados a balanços e estados de arte, além da publicação de coletâneas com interesse específico na relação emoções, cultura e sociedade.

É importante também ressaltar o trabalho ininterrupto de pesquisadores ligados às áreas aqui trabalhadas, de produção e manutenção nos congressos e encontros nacionais e latino-americanos de grupos de trabalho, oficinas, mesas redondas e fóruns nas áreas de antropologia e de sociologia das emoções. As perguntas que se encontram por trás desse esforço são: o que se pode fazer para canalizar e organizar a demanda crescente de interesse sobre a questão das emoções, vistas nos encontros e congressos que reúnem grupos de trabalho sobre a temática, com fins de discussão, organização e consolidação destas áreas disciplinares? Como focar o debate na problemática das emoções, mesmo quando nas comunicações apresentadas elas ainda aparecem como que subsumidas em discussões correlatas de gênero, de corpo, de moralidade?

Interesses conexos como os mencionados acima são fundamentais para a discussão da relação subjetividade e emoções na análise da cultura e sociedade, e são o fundamento da constituição disciplinar de uma antropologia e de uma sociologia das emoções. É através deles que os profissionais mais ativos na área devem atentar para a necessidade de encaminhamento do debate para a grande questão atual desse campo disciplinar, que é a sensibilização para o debate sobre a centralidade da categoria emoções para a análise social e cultural. Trazer as emoções como cerne no debate das ciências sociais, hoje, deste modo, é o grande desafio dos que fazem a antropologia e a sociologia das emoções.

Pela consolidação da sociologia e da antropologia das emoções no Brasil!

Abstract: This paper aims to conduct a brief overview of the situation of sociology and anthropology of emotions in Brazil, since its inception at the end of the first half of the 1990s to the present. It is based on, among other sources, in data collected at conferences and meetings in Brazil and Latin America, which had working groups in anthropology and sociology of emotions, or issues related to them.

Keywords: sociology of emotions; anthropology of emotions; state of art; consolidation of subject area. 


\section{Bibliografia temática}

ALMEIDA, Alexandre Paz. Sociabilidade, pertença e medos corriqueiros: estudo de uma rua no bairro de Valentina de Figueiredo, João Pessoa, Paraíba. 2005. Trabalho de Conclusão de Curso (Graduação em Ciências Sociais) - Universidade Federal da Paraíba, Conselho Nacional de Desenvolvimento Científico e Tecnológico. Orientador: Mauro Guilherme Pinheiro Koury.

BARRETO, Maria Cristina Rocha. Imagens da cidade. A ideia do progresso nas fotografias da cidade da Parahyba (1870-1930). 1996. Dissertação (Mestrado em Sociologia) - Universidade Federal da Paraíba, Coordenação de Aperfeiçoamento de Pessoal de Nível Superior. Orientador: Mauro Guilherme Pinheiro Koury.

BRITO, Simone. Metáforas do corpo e emoções no pensamento de Adorno. Revista Brasileira de Sociologia das Emoções, v. 11, n. 33, 2012, p. 655 a 672.

BRITO, Simone. Negative morality: Adorno's sociology. 2007. Tese. PhD em Sociologia. Lancaster University, Lancaster.

BRITO, Simone; MORAIS, J. V. ; BARRETO, T. V. . Regras do jogo vs. regras morais: para uma sociologia do fair play. Revista Brasileira de Ciências Sociais, v. 75, 2011, p. 133147.

CAMPOS. Roberta Bivar Carneiro; MAURICIO JR., Cleonardo. Os comensais da palavra. Emoções e corpo na trajetória espiritual dos crentes da Assembleia de Deus. Revista Brasileira de Sociologia da Emoção, v. 11, n. 33, Dez. 2012, p. 800-828.

CAVALCANTE FILHO, Francisco de Assis Vale. Convívio e interação social: os códigos de afeição e de estranhamento, os medos corriqueiros e a sociabilidade em uma rua. 2005. Trabalho de Conclusão de Curso (Graduação em Ciências Sociais) - Universidade Federal da Paraíba, Conselho Nacional de Desenvolvimento Científico e Tecnológico. Orientador: Mauro Guilherme Pinheiro Koury.

CERTEAU, Michel de. L'invention du quotidien. 1. Arts de faire. Paris: Gallimard, 1990.

COELHO, Edson Bertoldo. Construindo soldados: uma análise do processo de formação dos soldados da Polícia Militar da Paraíba. 2006. Trabalho de Conclusão de Curso (Graduação em Ciências Sociais) - Universidade Federal da Paraíba. Orientador: Mauro Guilherme Pinheiro Koury.

COELHO, Maria Claudia. Dádiva e emoção: obrigatoriedade e espontaneidade nas trocas materiais. Revista Brasileira de Sociologia da Emoção, v. 2, n. 6, Dez. 2003.

COELHO, Maria Claudia. O valor das intenções. Dádiva, emoção e identidade. Rio de Janeiro: Editora FGV, 2006. 
COELHO, Maria Claudia. Emoção, gênero e violência: experiências e relatos de vitimização. Revista Brasileira de Sociologia da Emoção, v. 5, n. 13, Abr. $2006 a$.

. Narrativas da violência: a dimensão micropolítica das emoções. Mana, v. 16, n. 2, 2010, p. 265-285. <http://www.scielo.br/pdf/mana/v16n2/01.pdf>.

- Gênero, emoções e vitimização: percepções sobre a violência urbana no Rio de Janeiro. Sexualidad, Salud y Sociedad, v. 10, 2012, p. 10-36.

CORREIA, Luiz Gustavo Pereira de Souza. Imagem fotográfica e memória: Templo de Angola Xangô Catulho Onicá no Zambe através de um acervo particular de fotografias. 2002. Dissertação (Mestrado em Sociologia) - Universidade Federal da Paraíba, Conselho Nacional de Desenvolvimento Científico e Tecnológico. Orientador: Mauro Guilherme Pinheiro Koury.

DA MATTA, Roberto. Carnavais, malandros e heróis: para uma sociologia do dilema brasileiro. Rio de Janeiro: Zahar, 1979.

DANTAS, José Alberto Grisi. Eutanásia e consciência de morte. Notas com vistas à subjetividade da questão eutanásia. 2001. Trabalho de Conclusão de Curso (Graduação em Ciências Sociais) - Universidade Federal da Paraíba. Orientador: Mauro Guilherme Pinheiro Koury.

ELIAS, Norbert. O processo civilizador. Rio de Janeiro: Jorge Zahar, 1990.

FARIAS JR., Edísio Ferreira de. Fotojornalismo de homicídio: uma leitura compreensiva - Folha de Pernambuco 1999/2000. 2001. Trabalho de Conclusão de Curso (Graduação em Ciências Sociais) - Universidade Federal da Paraíba, Conselho Nacional de Desenvolvimento Científico e Tecnológico. Orientador: Mauro Guilherme Pinheiro Koury.

GALVÃO, Patrícia Carla Smith. Experiência emocional de indivíduos em situação de rua no Centro Antigo de Salvador. Anais XV Ciso Encontro Norte e Nordeste de Ciências Sociais Pré-Alas Brasil, 2012.

GALVÃO, Patrícia Carla Smith; SOUSA, Leliana Santos de. La educación contra la marginalización de los niños em la "Escola Comunitária Luiza Mahin" en el barrio de los Alagados, Salvador, Bahia, Brasil. In: VIII Congreso Internacional de Educación Superior, 2012, Habana.

KEMPER, Theodore D. Themes and variations in the sociology of emotions. In: KEMPER, T. D. (Org.). Research agendas in the sociology of emotions. New York: State University of New York Press, 1990, p. 3-23.

KOURY, Mauro Guilherme Pinheiro (Org.) Medos corriqueiros e sociabilidade. João Pessoa: EdUFPB; Edições do Grem, 2005b. 
—. Trabalho e disciplina (Os homens pobres nas cidades do Nordeste: 1889-1920). In: HARDMAN, Francisco Foot et alii (Org.). Relações de trabalho \& relações de poder: mudanças e permanências. Fortaleza: Imprensa Universitária UFC, 1986, p. 134 a 149.

. Diferenciação entre o bem e o mal: pobreza, violência e justiça. In: MOTTA, Alda B. et alii. Nordeste, o que há de novo? Natal: EdUFRN, 1988 , p. 147-149.

—. As violências invisíveis: Paraíba, 1993. Política \& Trabalho, n. 8/10, 1994, p. 3-12.

- Medos corriqueiros: em busca de uma aproximação metodológica. Cronos, v. 3, n. 1, 2002, p. 94-101.

—. Sociologia da emoção: o Brasil urbano sob a ótica do luto. Petrópolis: Vozes, 2003.

_. Introdução à sociologia da emoção. João Pessoa: Ed. Manufatura, 2004.

— A antropologia das emoções no Brasil. Revista Brasileira de Sociologia da Emoção, v. 4, n. 12, 2005, p. 239-252.

- Amor e dor: ensaios em antropologia simbólica. Recife: Edições Bagaço, 2005a..

- Sofrimento social: movimentos sociais na Paraíba através da Imprensa, 1964 a 1980. João Pessoa: EdUFPB; Edições do Grem, 2007.

- De que João Pessoa tem medo? Uma abordagem em antropologia das emoções. João Pessoa: EdUFPB; Edições do Grem, 2008.

- Emoções, sociedade e cultura. Curitiba: Ed. CRV, 2009.

- Relações delicadas: ensaios em fotografia e sociedade. João Pessoa: EdUFPB, 2010.

—. Práticas instituintes e experiências autoritárias. Rio de Janeiro: Garamond, 2012.

KOURY, Mauro Guilherme Pinheiro; ZAMBONI, Marcela; BRITO, Simone. 2010. Confiança e vergonha: uma análise do cotidiano da moralidade. Trabalho completo apresentado no GT 32 Antropologia e Sociologia da Moral, no XXXIV Encontro da Anpocs. Anais do XXXIV Encontro da Anpocs. <http://www.anpocs.org/portal/index.php?option=com_docman\&task=doc_view\&gid=1673\&ltemid=350>.

KUPER, Adam. Cultura: a visão dos antropólogos. Bauru: EdUSC, 2002.

LIRA, Bertrand de Souza. Fotografia na Paraíba: um Inventário dos fotógrafos através do retrato (1850-1950). 1997. Dissertação (Mestrado em Sociologia) - Universidade Federal da Paraíba, Coordenação de Aperfeiçoamento de Pessoal de Nível Superior. Orientador: Mauro Guilherme Pinheiro Koury. 
LUTZ, Catherine; WHITE, Geoffrey M. The anthropology of emotions. Annual Review of Anthropology, v. 15, 1986, p. 405-436.

MACIEL, Fabrício. O Brasil-nação como ideologia: a construção retórica e a sociopolítica da identidade nacional. São Paulo: Annablume, 2007.

OLIVEIRA, Rossana Cristina Honorato de. Se essa cidade fosse minha... A experiência urbana na perspectiva dos produtores culturais de João Pessoa. 1999. Dissertação (Mestrado em Sociologia) - Universidade Federal da Paraíba, Coordenação de Aperfeiçoamento de Pessoal de Nível Superior. Orientador: Mauro Guilherme Pinheiro Koury.

PINA CABRAL, João de. A pessoa e o dilema brasileiro: uma perspectiva anticesurista. Novos Estudos, n. 78, 2007, p. 95-111.

RETONDAR, Anderson Moebus. Sociedade de consumo, modernidade e globalização. São Paulo: Annablume, 2007.

A (re) construção do indivíduo: a sociedade de consumo como "contexto social" de produção de subjetividade. Sociedade e Estado, v. 23, 2008, p. 137-160.

- Hibrismo cultural: clave analitica para la compreensión de la modernización latinoamericana? la perspectiva de Néstor García Canclini. Sociológica (México), v. 23, 2008a, p. 34-49.

_. O consumo do "eu" e o "Eu" do consumo: fetichismo e subjetividade na sociedade contemporânea. Política \& Trabalho (UFPB. Impresso), v. 1, 2009, p. 145-155.

— Para além do princípio do prazer: hedonismo e subjetividade na contemporânea sociedade de consumo. Revista Brasileira de Sociologia da Emoção (Online), v. 11, 2012, p. 234-251.

—. 2002a. Mágoas de amizade: um ensaio em antropologia das emoções. Mana, vol.8, n.2, pp. 69-89.

- 2003. O brasileiro emotivo: reflexões sobre a construção de uma identidade brasileira. RBSE- Revista Brasileira de Sociologia da Emoção, v. 2, n. 4, Abril.

REZENDE, Claudia Barcellos. Os significados da amizade. Duas visões de pessoa e sociedade. Rio de Janeiro: Ed. FGV, 2002.

Saudades de casa? Identidade nacional no prisma da antropologia das emoções. Revista Brasileira de Sociologia da Emoção, v. 5, n. 14/15, Dez. 2006.

- Stereotypes and national identity: experiencing the emotional Brazilian. Identities (Yverdon), v. 15, 2008, p. 103-122. 
- Um estado emotivo: representação da gravidez na mídia. Cadernos Pagu (Unicamp. Impresso), v. 36, 2011, p. 315-344.

- The experience of pregnancy: subjectivity and social relations. Vibrant (Florianópolis), v. 8, 2011a, p. 529-549.

. Emoção, corpo e moral em grupos de gestante. Revista Brasileira de Sociologia da Emoção (Online), v. 11, 2012, p. 830-849.

REZENDE, Claudia Barcellos; COELHO, Maria Claudia. Antropologia das emoções. Rio de Janeiro: Ed. FGV, 2010.

RÖTTGER-RÖSSLER, Birgitt. Emoção e cultura: algumas considerações básicas. Revista Brasileira de Sociologia da Emoção (Online), v. 7, n. 20, 2008, p. 177-220.

SANTOS, Maria Sandra Rodrigues dos. O luto e a representação da morte na cidade de João Pessoa. 2000. Trabalho de Conclusão de Curso. (Graduação Ciências Sociais) Universidade Federal da Paraíba. Orientador: Mauro Guilherme Pinheiro Koury.

SANTOS, Maria Sandra Rodrigues dos. Um espaço relacional? Rituais da morte no bairro da Ilha do Bispo, João Pessoa, Paraíba. 2002. Dissertação (Mestrado em Sociologia) - Universidade Federal da Paraíba, Conselho Nacional de Desenvolvimento Científico e Tecnológico. Orientador: Mauro Guilherme Pinheiro Koury.

SANTOS, Sandra Regina Rodrigues dos. A morte e os rituais fúnebres do Bairro do Roger. 2001. Trabalho de Conclusão de Curso (Graduação em Ciências Sociais) - Universidade Federal da Paraíba. Orientador: Mauro Guilherme Pinheiro Koury.

SILVA, Andréia Vieira da. Sob a ótica do medo: um estudo de caso no Bairro dos Estados, João Pessoa, Paraíba. 2004. Trabalho de Conclusão de Curso (Graduação em Ciências Sociais) - Universidade Federal da Paraíba. Orientador: Mauro Guilherme Pinheiro Koury.

SILVA, Patrick Cezar da. Memória social e sentimento de pertença: um estudo sobre o Parque Solon de Lucena. 2006. Trabalho de Conclusão de Curso. (Graduação em Ciências Sociais) - Universidade Federal da Paraíba, Universidade Federal da Paraíba. Orientador: Mauro Guilherme Pinheiro Koury.

SILVA, Rivamar Guedes da. Tambiá - medo, cultura e sociabilidade: um estudo sobre o Bairro do Tambiá, João Pessoa - PB. 2003. Trabalho de Conclusão de Curso (Graduação em Ciências Sociais) - Universidade Federal da Paraíba, Conselho Nacional de Desenvolvimento Científico e Tecnológico. Orientador: Mauro Guilherme Pinheiro Koury. 
SOUSA, Anne Gabriele Lima. Tambaú: pertença e fragmentação. Sob uma ótica do medo. 2004. Trabalho de Conclusão de Curso (Graduação em Ciências Sociais) - Universidade Federal da Paraíba, Conselho Nacional de Desenvolvimento Científico e Tecnológico. Orientador: Mauro Guilherme Pinheiro Koury.

SOUZA, Alessa Cristina Pereira de. Medo e sociedade: uma análise do bairro de Cruz das Armas, JP, PB. 2003. Trabalho de Conclusão de Curso (Graduação em Ciências Sociais) - Universidade Federal da Paraíba, Conselho Nacional de Desenvolvimento Científico e Tecnológico. Orientador: Mauro Guilherme Pinheiro Koury.

SOUZA, Jessé de. Roberto Da Matta e a vertente culturalista da nossa sociologia da inautenticidade. In: SOUZA, Jessé de. A modernização seletiva: uma reinterpretação do dilema brasileiro. Brasília: EdUnB, 2000, p. 183-204.

- A sociologia dual de Roberto Da Matta: descobrindo nossos mistérios ou sistematizando os nossos enganos? Revista Brasileira de Ciências Sociais, v. 16, n. 45, 2001, p. 47-67.

SOUZA, Leandro Cunha de. João Pessoa à noite. Um estudo sobre vida noturna e sociabilidade, 1920 a 1980. 2005. Trabalho de Conclusão de Curso (Graduação em Ciências Sociais) - Universidade Federal da Paraíba. Orientador: Mauro Guilherme Pinheiro Koury.

SOUZA, Liliane Cunha de. Ato fotográfico: sociabilidade e significação de mundo. 2001. Trabalho de Conclusão de Curso (Graduação em Ciências Sociais) - Universidade Federal da Paraíba, Conselho Nacional de Desenvolvimento Científico e Tecnológico. Orientador: Mauro Guilherme Pinheiro Koury.

SVASEK, Maruska. Introduction: anthropology of emotions. In: MILTON, Kay; SVASEK, Maruska (Orgs.). Mixed emotions. Oxford: Berg Publisher, 2006, p. 1-23.

TORRES, Marieze Rosa. Hóspedes incômodas: as emoções na sociologia norte-americana. 2009. Tese (Doutorado) - Programa de Pós-Graduação em Ciências Sociais, Universidade Federal da Bahia, Salvador.

VELHO, Gilberto. Individualismo e cultura. Rio de Janeiro: Jorge Zahar, 1981.

—. Subjetividade e sociedade. Rio de Janeiro: Jorge Zahar, 1986.

ZAMBONI, Marcela. "Quem acreditou no amor, no sorriso e na flor": a confiança nas relações amorosas. São Paulo: Annablume, 2010. 